\title{
Higher degree-days at the time of breeding predict size of second clutches in the barn swallow
}

\author{
Roberto Ambrosini ${ }^{1, *}$, Nicola Saino ${ }^{2}$, Diego Rubolini' ${ }^{2}$, Anders Pape Møller ${ }^{3}$ \\ ${ }^{1}$ Dipartimento di Biotecnologie e Bioscienze, Università degli Studi di Milano-Bicocca, piazza della Scienza 2, 20126 Milan, Italy \\ ${ }^{2}$ Dipartimento di Biologia, Università degli Studi di Milano, via Celoria 26, 20133 Milan, Italy \\ ${ }^{3}$ Laboratoire d'Ecologie, Systématique et Evolution, CNRS UMR 8079, Université Paris-Sud, Bâtiment 362,91405 Orsay \\ Cedex, France
}

\begin{abstract}
Failure to adjust timing of biological events to ongoing rapid climate change may incur negative fitness consequences for organisms and may have severe negative consequences for population viability. We studied long-term trends in breeding phenology and reproductive success of a barn swallow Hirundo rustica population during 1971-2009 in relation to spring accumulated temperature (degree-days). Degree-days at the time of a phenological event constitute a more accurate and meaningful measure of the biological environment than mean temperatures over fixed time intervals, because accumulated temperature determines seasonal development, emergence and reproduction of many organisms, including the invertebrates on which species at higher trophic levels feed. Although laying dates showed an inverted U-shaped trend over time, degree-days at laying of first and second clutches increased linearly, suggesting that barn swallows are becoming increasingly ecologically mismatched relative to spring events. In addition, higher degree-days at laying were associated with smaller second clutches. These findings suggest that barn swallows are currently delaying reproduction relative to spring phenology, with negative consequences for their reproductive output. This delay may thus contribute to the population decline observed over the last decades. Degree-days at the time of reproduction may therefore provide a mechanistic link between phenology, breeding success and demographic trends of migratory bird populations.
\end{abstract}

KEY WORDS: Degree-days · Ecological mismatch · Fecundity · Hirundo rustica $\cdot$ Phenology · Thermal delay

Resale or republication not permitted without written consent of the publisher

\section{INTRODUCTION}

Climate change is currently occurring at a very fast rate, with global temperature and local temperature estimates exceeding anything observed during the last few hundred years (IPCC 2007). Consequences of such a rate of change have been documented on the distribution and abundance, morphology and life-histories of organisms and on their ecological interactions (Parmesan \& Yohe 2003, IPCC 2007, Møller et al. 2010a, Peterson et al. 2010).

In seasonal environments, timing of reproduction is often adjusted so as to coincide with optimal abiotic conditions and the peak availability of food (Lack 1954). Because climate change can affect seasonal variation in food abundance, organisms may have to shift their phenology (i.e. the timing of their life-cycle events) in order to retain an appropriate match to their food sources (Both et al. 2009, Both 2010); failure to do so may have negative repercussions on individual fitness and thus on population viability (Møller et al. 2008).

In temperate and high latitudes, the phenology of plants and ectotherms largely depends on the accumulated sum of temperatures above a critical threshold over a time period (degree-days), which allows 
development, growth or other essential aspects of normal functioning of all living organisms (Schwartz 2003). Many studies have used degree-days to investigate a broad range of phenomena in ecology and agronomy ranging from change in distribution range (e.g. Beale et al. 2008, Huntley 2008), plant water stress (e.g. Jackson et al. 1981), plant and animal development (e.g. Chapman 1988, Bonhomme 2000), feeding ecology of insects (e.g. Cummins \& Klug 1979) and insect pest management (e.g. Preuss 1983, Ritchie 2000). Degree-days may thus provide a useful tool for assessing to what extent phenological stages are biologically early or late relative to the phenology of critical resources (Saino et al. 2011).

Because of thermal control of life-cycle events ('phenophases'), plants and insects may have advanced their phenophases to an extent that allows them to fully compensate for climate warming, whereas organisms at higher trophic levels may have not, as the ability to track variation in spring phenology may be constrained by other life history traits. For example, it has been suggested that migration over long distances can hinder adaptive phenological shifts of birds (Both \& Visser 2001, Rubolini et al. 2010, Saino et al. 2011). This may result in mis-timing between phenophases if organisms at upper trophic levels do not track directional shifts in phenophases of their prey (Both et al. 2009, Saino et al. 2011).

Recently Saino et al. (2011) tested for long-term trends of degree-days at mean arrival dates of migratory birds to their breeding grounds in northern Europe, showing that migrants now arrive at higher degree-days than in the past. Moreover, migrants that have experienced the largest 'thermal delay' (i.e. those for which degree-days at arrival increased the most) have also undergone the largest population declines (Saino et al. 2011).

In this study, we used a $40 \mathrm{yr}$ time series of laying dates and clutch size in a Danish population of barn swallows Hirundo rustica to investigate whether degree-days at the time of reproduction have changed over time. In particular, an increase in degree-days at reproduction, as may be expected under a climate warming scenario, would imply that barn swallows now breed relatively late compared to spring phenology than they did in the past, whereas a decrease would instead indicate a relatively earlier breeding (Saino et al. 2011). Finally, a lack of temporal trend in degree-days at reproduction would indicate that barn swallows have maintained the matching of timing of reproduction relative to spring phenophases under a period of climate warming.

\section{MATERIALS AND METHODS}

\subsection{Study organism}

The barn swallow is a ca. $18 \mathrm{~g}$ aerially insectivorous passerine with a wide breeding range in the temperate and subtropical regions of the northern hemisphere (Cramp 1988, Møller 1994a, Turner 2006). Barn swallows arrive from spring migration to the study area in Denmark in April to June and breed in May to August (Møller 1994a). Arrival dates have advanced during the last decades, possibly as a consequence of climate change, though at different rates for males and females (Møller 2004). Studies in the same area have demonstrated that the duration of the breeding season has increased (Møller et al. 2010b) due to an increase in the interval between first and second clutches (Møller 2007).

\subsection{Study area}

The study was carried out in Kraghede $\left(57^{\circ} 12^{\prime} \mathrm{N}\right.$, $\left.10^{\circ} 00^{\prime} \mathrm{E}\right)$, Denmark. The study area consists of ca. $45 \mathrm{~km}^{2}$ of arable farmland habitat with barn swallows breeding inside barns and cowsheds, and only rarely elsewhere, e.g. under bridges. This population of barn swallows has been the subject of a long-term study initiated in 1971 (Møller 1994a).

Farms in this area are separated by 75 to $3000 \mathrm{~m}$ (distance between farm centres). The fields and scattered trees around farms comprise most of the area, with the exception of a few orchards, ponds, ditches and streams. The main crops are grass, barley, wheat and potatoes. The range in altitude is 9 to $28 \mathrm{~m}$ a.s.l. (see Møller 1994a for a thorough description of the study area).

Mean monthly temperature in the area ranges from $6.2^{\circ} \mathrm{C}$ in April to $16.1^{\circ} \mathrm{C}$ in July, with an overall mean of $12.6^{\circ} \mathrm{C}$ for April to August. Mean monthly rainfall varies from a minimum of $36 \mathrm{~mm}$ in April to $71 \mathrm{~mm}$ in August, with a mean of $276 \mathrm{~mm}$ in April to August.

\subsection{Laying date and clutch size}

Adults were matched with nests using colour rings and individual patterns of colour markings on breast and belly feathers, a method that is commonly adopted in studies of barn swallows (see e.g. Møller 1994a, Saino et al. 1999, 2002, Buchanan \& Evans 2000, Møller et al. 2004). We recorded laying date in individual nests as the date of laying of the first egg, 
clutch size as the maximum number of eggs in the nest, and brood size as the number of fledglings for both first and second clutches, when a second clutch was found. The proportion of pairs having a second clutch was also recorded in each year. In all analyses, we used mean within-year values of laying date and clutch size.

Nests were monitored at least weekly - and during laying and hatching at shorter intervals - to determine laying date and reproductive success. Clutch size was the number of eggs present on the first nest check during the incubation period. We used clutch size as a proxy of reproductive success, as barn swallows adopt a brood-survival strategy whereby $>90 \%$ of all eggs result in fledged young (Møller 1994a). In addition, nestling mortality is mainly caused by predation or infanticide (Møller 1994a). Hence, in this species, clutch size should reflect parental decisions over investment in reproduction more reliably than brood size, as the latter is more affected by events unrelated to constraints on breeding due to environmental conditions.

\subsection{Temperature data}

Temperature data were obtained from the ERA-40 (Uppala et al. 2005) and ERA-Interim (Simmons et al. 2006) reanalysis projects (see www.ecmwf.int/ research/era/do/get/index) of the European Centre for Medium Range Forecasts for 1971-2001 and 2002-2009, respectively, on a $1.125^{\circ}$ latitude $\times 1.125^{\circ}$ longitude grid for 0:00, 6:00, 12:00 and 18:00 h of all days. The use of different data sources is justified, as the ERA-Interim data did not include years before 1989, and ERA-40 data did not include years after 2001 (see also Saino et al. 2011). For each year, we computed the degree-days as the sum of the instantaneous temperatures $>+6^{\circ} \mathrm{C}$ from 1 January to the mean day of laying (rounded to the closest integer) of first or second clutches, and divided this sum by 4 (i.e. the number of instantaneous temperature estimates per day in ERA-40 and ERA-Interim data). This way of calculating degree-days gives a more reliable estimate of the accumulated temperature actually experienced by insects than an estimate based on mean daily temperature, because insect development occurs even during short periods when the temperature is above the minimum temperature required for their development (Schwartz 2003).

Degree-day values at mean laying date of first or second clutches (Bre1DD and Bre2DD, respectively), computed using 2 different temperature thresholds $\left(+3\right.$ or $\left.+6^{\circ} \mathrm{C}\right)$ were highly positively correlated (Bre1DD: $\mathrm{r}=0.91$; Bre2DD: $\mathrm{r}=0.95 ; \mathrm{N}=39 \mathrm{yr}$ in both cases). We thus present only analyses based on degree-days above $+6^{\circ} \mathrm{C}\left(\mathrm{Bre}_{\mathrm{DDD}} \mathrm{D}_{+6}\right.$ and $\left.\mathrm{Bre} 2 \mathrm{DD}_{+6}\right)$, as degree-days computed at the higher threshold may be more relevant to the insect food of barn swallows (Schwartz et al. 2006).

\subsection{Statistical analyses}

We first analysed temporal trends in laying date, clutch size, degree-days at laying date and proportion of pairs having a second brood (arcsine square root transformed) of each year by generalised least squares models that accounted for possible temporal autocorrelation in the time series data (Zuur et al. 2009). Temporal autocorrelation is rarely considered in ecological studies of climate change (Lindström \& Forchhammer 2010), although neglecting it may seriously bias statistical analyses (Zuur et al. 2009). A first-order residual autocorrelation structure was used in all models. The second-order polynomial term of year was also included as a predictor to model non-linear trends.

We then repeated all analyses while also including degree-days above $+6^{\circ} \mathrm{C}\left(\mathrm{Bre}_{1 \mathrm{DD}} \mathrm{D}_{+6}\right.$ or $\left.\mathrm{Bre} 2 \mathrm{DD}_{+6}\right)$ as a predictor, in order to test for the effect of degreedays at laying of first or second clutches while controlling for long-term non-linear temporal trends.

Analyses were performed with the gls procedure in the nlme library (Pinheiro et al. 2008) in R 2.8.1 (R Development Core Team 2008).

\section{RESULTS}

\subsection{Temporal trends in degree-days at the time of reproduction}

Over a 39 yr period (1971-2009), the mean laying date of both first and second clutches showed an inverted U-shaped temporal trend with a latest estimated mean laying date in 1983 for first clutches and 1994 for second clutches (Table 1, Fig. 1). During the same period, both Bre1DD ${ }_{+6}$ and Bre2DD $\mathrm{D}_{+6}$ increased significantly and linearly $\left(\mathrm{Bre}_{1 \mathrm{DD}} \mathrm{D}_{+6}\right.$ : estimate: $1.373 \pm 0.586 \mathrm{SE}_{2} t_{37}=2.34, \mathrm{p}=0.025 ; \mathrm{Bre}_{2 \mathrm{DD}}{ }_{+6}$ : estimate: $4.978 \pm 1.019, t_{37}=4.88, \mathrm{p}<0.001$; Fig. 2), while the second order polynomial term of year was never significant $\left(\right.$ Bre1DD $_{+6}: t_{36}=0.43, \mathrm{p}=0.669 ;$ Bre2DD $_{+6}$ : $t_{36}=1.07, \mathrm{p}=0.290$ ). The laying date of first clutches therefore advanced by approximately $7 \mathrm{~d}$ since 1971 
Table 1. Hirundo rustica. Temporal trends of mean laying date $( \pm$ SE) of first and second clutches. Sample size is $39 \mathrm{yr}$ in both cases. Variable 'Year' was rescaled assuming $1990=$ 0 . $\varphi$ : first order temporal autocorrelation. Year²: 2nd order polynomial of the Year term

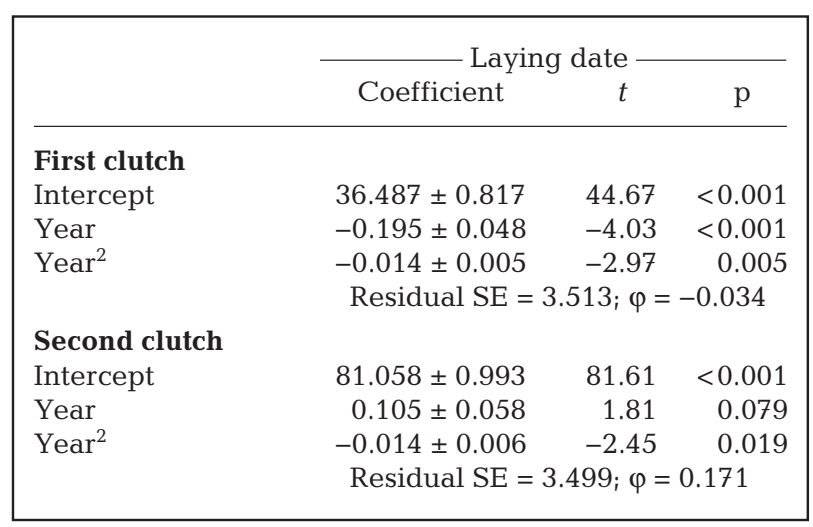

and by approximately $9 \mathrm{~d}$ since 1983, while that of the second clutches showed a delay of approximately $8 \mathrm{~d}$ from 1971 until 1994, and then slightly advanced by $3 \mathrm{~d}$ until 2009 .

The proportion of barn swallow pairs (arcsine square root transformed) that produced a second clutch did not change during 1971-2009 (quadratic term of year: $t_{36}=0.86, \mathrm{p}=0.395$; linear term after removal of the quadratic term; $t_{37}=-1.39, \mathrm{p}=0.174$; Fig. 3), and was not affected by $\operatorname{Bre} 1 \mathrm{DD}_{+6}\left(t_{37}=-0.91\right.$, $\mathrm{p}=0.371)$ or Bre2DD $\mathrm{D}_{+6}\left(t_{37}=-1.03, \mathrm{p}=0.309\right)$.

\subsection{Effects of degree-days at the time of reproduction on clutch size}

The size of both first and second clutches showed an inverted U-shaped pattern of change during the same period (Table 2, Fig. 4). There were no significant effects of Bre1DD ${ }_{+6}$ on size of first clutches, while the size of second clutches showed a significant negative relationship with $\mathrm{Bre}_{2} \mathrm{DD}_{+6}$ also after controlling for the significant non-linear trend of variation in clutch size (Table 2, Fig. 5). In addition, the relationship between $\mathrm{Bre}_{2 \mathrm{DD}}{ }_{+6}$ and size of second clutches remained significant even when extreme or high-leverage points (see Fig. 5) were excluded from the analysis $\left(t_{34} \leq-2.16, \mathrm{p} \leq 0.038\right.$ in all cases).

The model of the difference in mean size between first and second clutches (including first- and secondorder polynomial terms of year as predictors) showed that the size of second clutches was smaller, relative to first clutches, in years with large Bre2DD ${ }_{+6}$ (effect of Bre2DD ${ }_{+6}: t_{35}=-2.22, \mathrm{p}=0.033$; other details not shown).

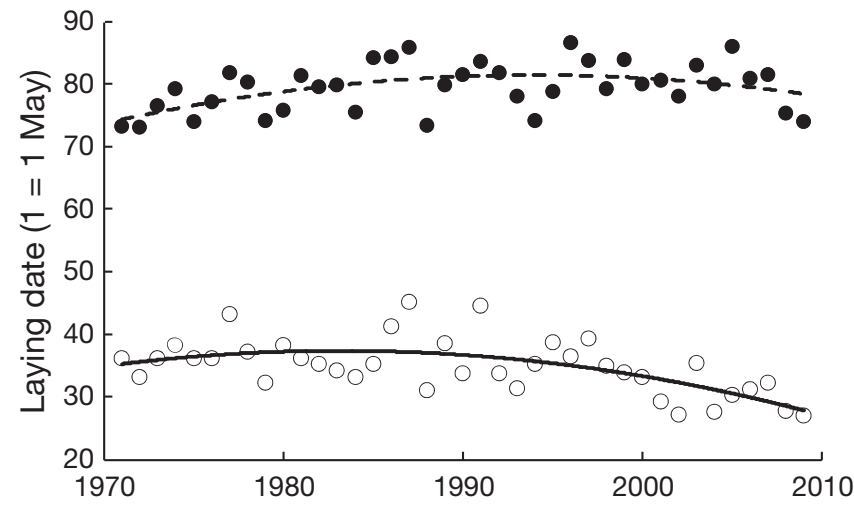

Fig. 1. Hirundo rustica. Mean laying date of first (open circles) and second (filled circles) clutches during 1971-2009 ( 1 = 1 May). The non-linear trends are drawn according to the parameters estimated by second-order polynomial regression models on year (see Table 1)

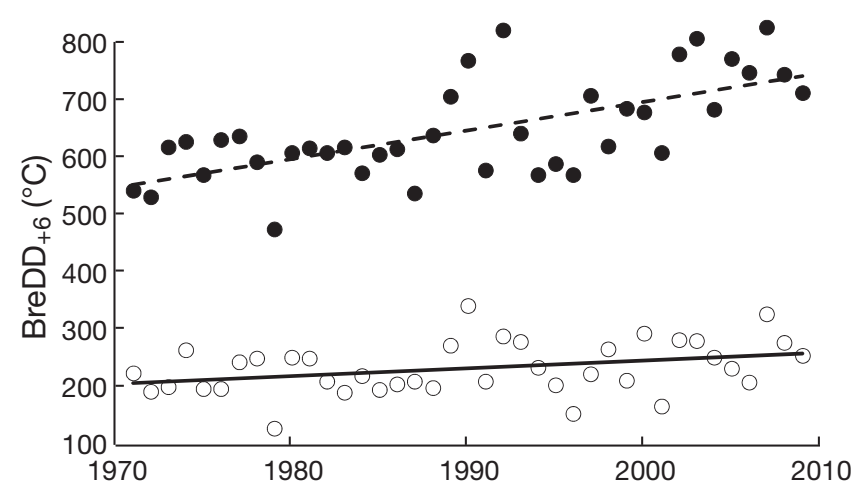

Fig. 2. Hirundo rustica. Degree-days above $+6^{\circ} \mathrm{C}$ at mean laying date $\left(\mathrm{BreDD}_{+6}\right)$ of first (open circles) and second (filled circles) clutches during 1971-2009. Linear regression lines are shown

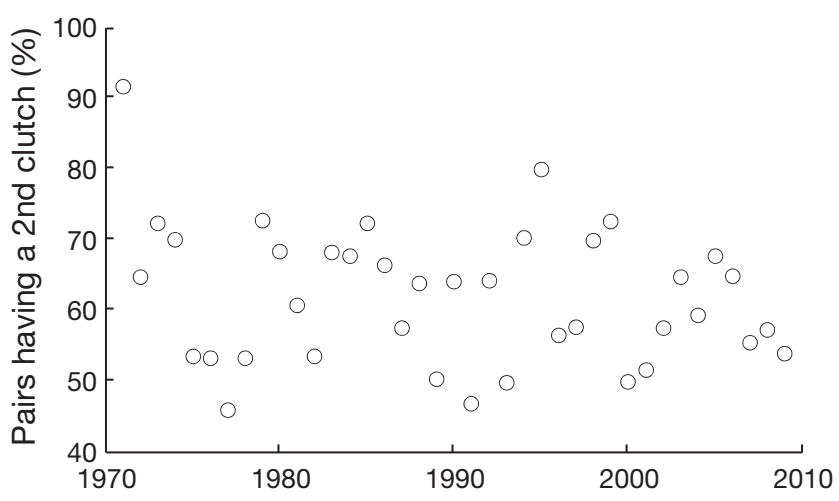

Fig. 3. Hirundo rustica. Proportion of pairs that produced a second clutch during 1971-2009

We estimated the effect of a change in $B r e 2 \mathrm{DD}_{+6}$ on the size of the second clutch. A change in Bre2DD+6 from $-2 \mathrm{SD}$ to $+2 \mathrm{SD}$ from the mean can be estimated to produce a reduction in size of second clutches by 
Table 2. Hirundo rustica. Mean $( \pm \mathrm{SE})$ size of first and second clutches in relation to first- and second-order polynomial terms of year (Year and Year $^{2}$ ) and degree-days above $+6^{\circ} \mathrm{C}$ at mean laying date of first $\left(\right.$ Bre1DD $\left._{+6}\right)$ or second $\left(\mathrm{Bre}_{2 \mathrm{DD}}{ }_{+6}\right) \mathrm{clutches}$. Sample size is $39 \mathrm{yr}$ for both first and second clutches. Variable 'Year' was rescaled assuming $1990=0$. $\varphi$ : first order temporal autocorrelation

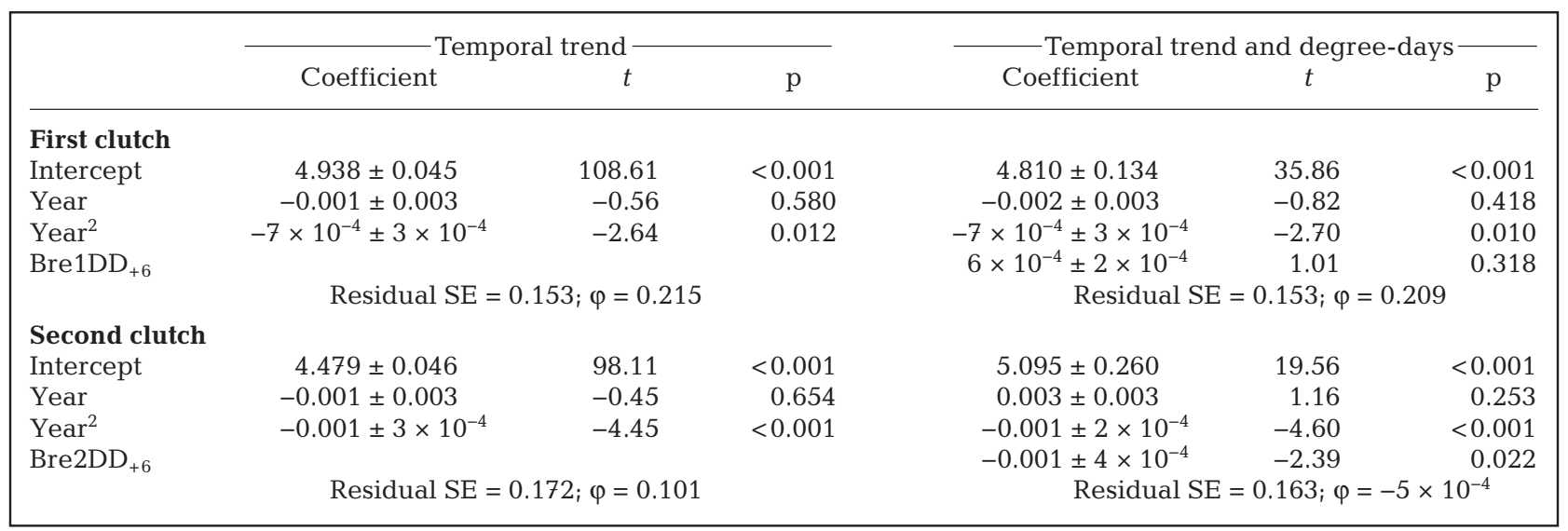

0.336 eggs, which corresponds to $156 \%$ of the SD of clutch size for second clutches during 1971-2009.

Thus, an increase in degree-days at breeding did not affect the proportion of breeding pairs of barn swallows that had a second clutch, but reduced the size of the second but not of the first clutches.

\section{DISCUSSION}

The main results of this study investigating variation in breeding phenology and reproductive success in a passerine bird in relation to an index of spring phenology were that (1) laying date and clutch size both changed in a non-linear fashion; (2) degreedays at laying of both first and second clutches increased over time; (3) higher degree-days at laying were associated with smaller second clutches relative to first clutches; and (4) the proportion of pairs

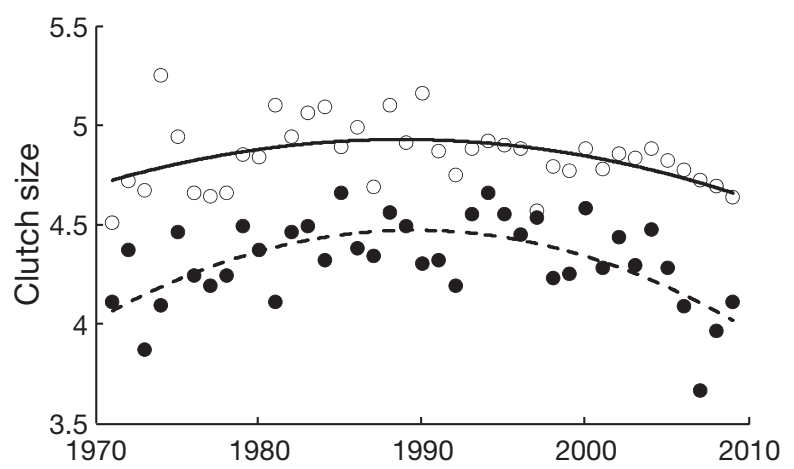

Fig. 4. Hirundo rustica. Mean size of first (open circles) and second (filled circles) clutches during 1971-2009. The nonlinear trends are drawn according to the parameters estimated by second-order polynomial regression models (see Table 2) that had a second clutch did not change during the study period and was unaffected by degree-days.

Large degree-day values at laying of first clutches imply that breeding occurs at later stage of the phenophases of plants and invertebrates, because their phenology is largely controlled by temperature accumulation during winter and early spring (Schwartz 2003). Hence, long-term increases in degree-days at breeding may be taken as a symptom that barn swallows have accumulated a 'thermal delay' (Saino et al. 2011) relative to insects, likely including their prey, and have therefore become increasingly ecologically mis-timed. In the present study, we assumed that a long-term increase in degree-days at reproduction results in an (increasing) ecological mismatch, and

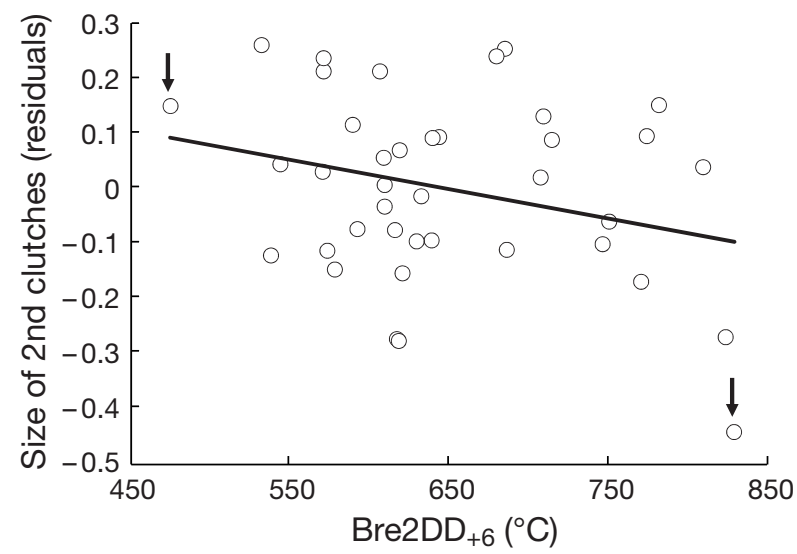

Fig. 5. Hirundo rustica. Size of second clutches (residuals from a second-order polynomial regression on year; see Table 2) in relation to degree-days above $+6^{\circ} \mathrm{C}$ at mean laying date of second clutches $\left(\mathrm{Bre}_{2} \mathrm{DD}_{+6}\right)$. The linear trend is fitted by simple regression of residuals on Bre2DD ${ }_{+6}$. Arrows: extreme points that were alternately excluded from the dataset to check for the robustness of the analysis 
regarded the alternative possibility that ecological matching increases with increasing degree-days at reproduction as unlikely (Saino et al. 2011). Indeed, selection for earlier breeding has been documented in several studies (Newton 2008), including barn swallows (Møller 1994a), suggesting that birds breed on average too late, rather than too early. In addition, birds are advancing their breeding date (Crick \& Sparks 1999, Dunn 2004, Lehikoinen et al. 2004, Rubolini et al. 2007, Saino et al. 2011), whereas the reverse should be expected if they were breeding too early. Finally, temperature changes have been occurring at a faster pace during recent decades than in previous ones (IPCC 2007) implying that birds are less likely to keep track of climate change in recent years. Thus, the temporal increase of degree-days at breeding suggests that barn swallows may be experiencing increasing levels of ecological mismatch.

Previous studies of migratory birds have suggested that increasing levels of ecological mismatch, as indexed either by direct measures of phenology of peak food abundance (generally insects; Both \& Visser 2001, Both et al. 2006) or by degree-day indices (Saino et al. 2011), may lead to a decrease in reproductive success that may ultimately affect population dynamics (Both et al. 2006, Møller et al. 2008). Here we showed that higher Bre $2 \mathrm{DD}_{+6}$ negatively affected reproduction of barn swallows via a negative effect on the size of second clutches, whereas Bre1DD ${ }_{+6}$ did not affect the size of first clutches.

An increase in degree-days at the time of reproduction therefore seems to have had a larger negative effect on barn swallow reproduction during the second, rather than the first clutch. This result is difficult to explain, as degree-days could be expected to have a larger effect on insect prey availability and on general environmental conditions at the beginning of the reproductive season rather than at later phases. It could be hypothesized that insect prey availability may be negatively affected by high degree-days at the time of second clutches, thus reducing the ability of parents to produce large second broods. Alternatively, the negative effect of degree-days on the size of second clutches may be due to carry-over effects whereby during the second clutch, the barn swallows pay the cost of having reared the first clutch under harsh ecological conditions. Indeed, Bre1DD+6 and Bre2DD ${ }_{+6}$ are positively correlated $(r=0.708)$, so that high degree-days at the time of second clutches also imply high degree-days at the time of first clutches. In addition, the mean size of first clutches is less variable than that of second ones in this population (coefficients of variation: first clutch $=0.03$, second clutch
$=0.05)$, thus suggesting that barn swallows are less likely to adjust the reproductive investment in first broods according to the ecological conditions faced at the beginning of the breeding season. Admittedly, these explanations are speculative, and further detailed studies are necessary to investigate the mechanisms linking degree-days and the size of second clutches. However, our study suggests that increasing levels of ecological mismatch may result in lower reproductive output, and therefore may add insights into the ecological mechanisms linking climate change to population dynamics.

Saino et al. (2011) recently demonstrated that those migratory species that have accumulated a large 'thermal delay' also showed negative population trends at their breeding grounds. In this barn swallow population, laying date parallels arrival date (Møller 1994a,b), so that a thermal delay at arrival also implies a thermal delay at reproduction, which in turn (probably by means of carry-over effects) depresses the breeding success of second broods (present study). Importantly, in years with a lower breeding success of second compared to first broods, the phenotypic quality of chicks from second broods was also lower (Møller 2002).

Understanding population response to climate change requires detailed studies of organisms' life cycle, and in particular of the effect of climate change on both birth and survival rates (Ådahl et al. 2006). This is difficult for the barn swallow, as survival of young individuals in their first year of life is subject to large uncertainty due to the low recruitment rate in the natal population (Turner 2006). However, a qualitative assessment of the overall population response to climate change can be drawn according to a general theoretical framework recently proposed by Ådahl et al. (2006), which indicates that if changes in climate conditions cause a reduction both in the survival and the birth rate, the population should suffer a 'climatically induced' reduction in size. The results from the present study indicate that reproductive output should decrease as a consequence of increased degree-days. In addition, climate change has probably reduced, rather than increased, the survival of barn swallows during the high mortality phases of migration and wintering (Ambrosini et al. 2011). Hence, despite a lack of detailed information on the impact of climate change on all stages of the life-cycle of the barn swallow, we can tentatively suggest that current climate change is negatively affecting this barn swallow population.

In conclusion, we have shown that degree-days at laying of first and second clutches have increased 
during 1971-2009, implying that plants, insects and other consumers may now emerge earlier with respect to barn swallow reproduction than just a couple of decades ago. Higher degree-days at laying were associated with smaller second clutches. Results from this study have therefore added insights into the mechanisms linking the ecological mismatch at the time of reproduction to population demography.

Acknowledgements. We thank 3 anonymous reviewers whose comments improved the quality of the manuscript.

\section{LITERATURE CITED}

Ådahl E, Lundberg P, Jonzén N (2006) From climate change to population change: the need to consider annual lifecycles. Glob Change Biol 12:1627-1633

Ambrosini R, Rubolini D, Møller AP, Bani L and others (2011) Climate change and the long-term northward shift in the African wintering range of the barn swallow Hirundo rustica. Clim Res 49:131-141

Beale CM, Lennon JJ, Gimona A (2008) Opening the climate envelope reveals no macroscale associations with climate in European birds. Proc Natl Acad Sci USA 105: 14908-14912

Bonhomme R (2000) Bases and limits to using 'degree-day' units. Eur J Agron 13:1-10

Both C (2010) Food availability, mistiming, and climatic change. In: Møller AP, Fiedler W, Berthold P (eds) Effects of climate change on birds. Oxford University Press, Oxford, p 129-147

Both C, Visser ME (2001) Adjustment to climate change is constrained by arrival date in a long-distance migrant bird. Nature 411:296-298

Both C, Bouwhuis S, Lessells CM, Visser ME (2006) Climate change and population declines in a long-distance migratory bird. Nature 441:81-83

Both C, van Asch M, Bijlsma RG, van den Burg AB, Visser ME (2009) Climate change and unequal phenological changes across four trophic levels: constraints or adaptations? J Anim Ecol 78:73-83

Buchanan KL, Evans MR (2000) The effect of tail streamer length on aerodynamic performance in the barn swallow. J Anim Ecol 11:228-238

> Chapman DW (1988) Critical review of variables used to define effects of fines in redds of large salmonids. Trans Am Fish Soc 117:1-21

Cramp J (1988) Handbook of the birds of Europe, the Middle East and North Africa. The birds of the Western Palearctic, Vol V. Oxford University Press, Oxford

Crick HQP, Sparks TH (1999) Climate change related to egg-laying trends. Nature 399:423

- Cummins KW, Klug MJ (1979) Feeding ecology of stream invertebrates. Annu Rev Ecol Syst 10:147-172

Dunn PO (2004) Breeding dates and reproductive performance. Adv Ecol Res 35:67-85

- Huntley B (2008) Plant species' response to climate change: implications for the conservation of European birds. Ibis 137:S127-S128

IPCC (Intergovernmental Panel on Climate Change) (2007) Climate change 2007: the physical science basis. Cambridge University Press, Cambridge
Jackson RD, Idso SB, Reginato RJ, Pinter PJ Jr (1981) Canopy temperature as a crop water stress indicator. Water Resour Res 17:1133-1138

Lack D (1954) The natural regulation of animal numbers. Clarendon, Oxford

Lehikoinen E, Sparks TH, Zalakevicius M (2004) Arrival and departure dates. In: Møller AP, Fiedler W, Berthold P (eds) Birds and climate change. Academic Press, London, p 1-31

Lindström J, Forchhammer MC (2010) Time-series analyses. In: Møller AP, Fiedler W, Berthold P (eds) Effects of climate change on birds. Oxford University Press, Oxford, p 57-66

Møller AP (1994a) Sexual selection and the barn swallow. Oxford University Press, Oxford

> Møller AP (1994b) Phenotype-dependent arrival time and its consequences in a migratory bird. Behav Ecol Sociobiol 35:115-122

> Møller AP (2002) North Atlantic Oscillation (NAO) effects of climate on the relative importance of first and second clutches in a migratory passerine birds. J Anim Ecol 71:201-210

> Møller AP (2004) Protandry, sexual selection and climate change. Glob Change Biol 10:2028-2035

- Møller AP (2007) Interval between clutches, fitness and climate change. Behav Ecol 18:62-70

Møller AP, Martinelli R, Saino N (2004) Genetic variation in infestation with a directly transmitted ectoparasite. J Evol Biol 17:41-47

Møller AP, Rubolini D, Lehikoinen E (2008) Populations of migratory bird species that did not show a phenological response to climate change are declining. Proc Natl Acad Sci USA 105:16195-16200

Møller AP, Fiedler W, Berthold P (eds) (2010a) Effects of climate change on birds. Oxford University Press, Oxford

Møller AP, Flensted-Jensen E, Klarborg K, Mardal W, Nielsen JT (2010b) Climate change affects the duration of the reproductive season in birds. J Anim Ecol 79:777-784

Newton I (2008) The migration ecology of birds. Academic Press, London

> Parmesan C, Yohe G (2003) A globally coherent fingerprint of climate change impacts across natural systems. Nature 421:37-42

> Peterson AT, Menon S, Xingong L (2010) Recent advances in the climate change biology literature: describing the whole elephant. Wiley Interdiscip Rev Clim Change 1: 548-555

Pinheiro J, Bates D, DebRoy S, Sarkar D, the R Core team (2008) nlme: linear and nonlinear mixed effects models. $\mathrm{R}$ package version 3. Available at http://cran.r-project. org/web/packages/nlme/nlme.pdf (accessed 10 April 2011)

Preuss KP (1983) Day-degree methods for pest management. Environ Entomol 12:613-619

R Development Core Team (2008) R: a language and environment for statistical computing. R Foundation for Statistical Computing, Vienna

Ritchie ME (2000) Nitrogen limitation and trophic vs. abiotic influences on insect herbivores in a temperate grassland. Ecology 81:1601-1612

Rubolini D, Ambrosini R, Caffi M, Brichetti P, Armiraglio S, Saino N (2007) Long-term trends in first arrival and first egg laying dates of some migrant and resident bird species in northern Italy. Int J Biometeorol 51:553-563

Rubolini D, Saino N, Møller AP (2010) Migratory behaviour constrains the phenological response of birds to climate change. Clim Res 42:45-55 
Saino N, Calza S, Ninni P, Møller AP (1999) Barn swallows trade survival against offspring condition and immunocompetence. J Anim Ecol 68:999-1009

Saino N, Incagli M, Martinelli R, Møller AP (2002) Immune response of male barn swallows in relation to parental effort, corticosterone plasma levels, and sexual ornamentation. Behav Ecol 13:169-174

Saino N, Ambrosini R, Rubolini D, von Hardenberg J and others (2011) Climate warming, ecological mismatch at arrival and population decline in migratory birds. Proc R Soc B Biol Sci 278:835-842

Schwartz MD (2003) Phenology. Kluwer Academic Publishers, Dordrecht

Editorial responsibility: Nils Chr. Stenseth, Oslo, Norway
Schwartz MD, Ahas R, Aasa A (2006) Onset of spring starting earlier across the Northern Hemisphere. Glob Change Biol 12:343-351

Simmons A, Uppala S, Dee D, Kobayashi S (2006) ERAInterim: new ECMWF reanalysis products from 1989 onwards. ECMWF, Shinfield Park

Turner A (2006) The barn swallow. T \& AD Poyser, London Uppala SM, Kållberg PW, Simmons AJ, Andrae U and others (2005) The ERA-40 re-analysis. QJR Meteorol Soc 131: 2961-3012

Zuur AF, Ieno EI, Walker NJ, Saveliev AA, Smith GM (2009) Mixed effects models and extensions in ecology with R. Springer, New York, NY

Submitted: May 13, 2011; Accepted: July 21, 2011

Proofs received from author(s): November 23, 2011 